\title{
Epidemiological, clinical and genetic aspects of adult onset isolated focal dystonia in Ireland
}

\author{
L. Williams \\ St Vincent's University Hospital \\ E. McGovern \\ St Vincent's University Hospital \\ O. Kimmich \\ St Vincent's University Hospital
}

See next page for additional authors

Follow this and additional works at: https://arrow.tudublin.ie/scschmatart

Part of the Mathematics Commons, and the Neurology Commons

\section{Recommended Citation \\ Williams L, McGovern E, Kimmich O, Molloy A, Beiser I, Butler JS, Molloy F, Logan P, Healy DG, Lynch T, Walsh R, Cassidy L, Moriarty P, Moore H, McSwiney T, Walsh C, O'Riordan S, Hutchinson M. Epidemiological, clinical and genetic aspects of adult onset isolated focal dystonia in Ireland. Eur $\mathrm{J}$ Neurol. 2017 Jan;24(1):73-81. doi: 10.1111/ene.13133. Epub 2016 Sep 19. PMID: 27647704.}

This Article is brought to you for free and open access by the School of Mathematics at ARROW@TU Dublin. It has been accepted for inclusion in Articles by an authorized administrator of ARROW@TU Dublin. For more information, please contact arrow.admin@tudublin.ie, aisling.coyne@tudublin.ie,gerard.connolly@tudublin.ie.

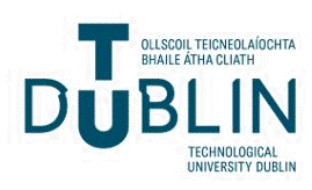




\section{Authors}

L. Williams, E. McGovern, O. Kimmich, A. Molloy, I. Beiser, John Butler, F. Molloy, P. Logan, D.G. Healy, T. Lynch, R. Walsh, L. Cassidy, P. Moriarty, H. Moore, T. McSwiney, C. Walsh, S. O'Riordan, and M. Hutchinson 
Janssen-Sponsored Satellite Symposium at the 37th ECTRIMS 2021

\section{The future is today: Reflecting on an optimized patient journey based on clinical scenarios}

This virtual satellite symposium focused on how to personalise treatment using prognostic profiling in multiple sclerosis (MS). It explored the evolving world of MS treatment through the use of dynamic patient cases and discussed the latest in prognostic biomarkers and cognitive testing, how COVID-19 vaccines fit into patients' priorities and how to account for patients' future family plans.

The symposium report has now been published in Key Opinions in Medicine
Access the publication

T. Key Opinions in Medicine

Neurology janssen $\rightleftharpoons$ Neuroscience of Gohnon-fohnon

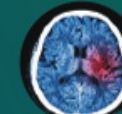




\title{
Epidemiological, clinical and genetic aspects of adult onset isolated focal dystonia in Ireland
}

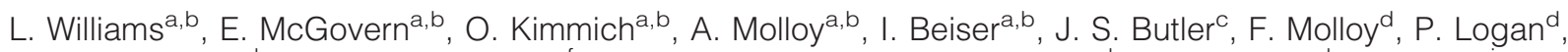

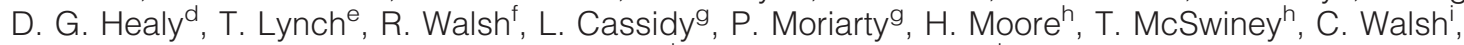 \\ S. O'Riordan ${ }^{\mathrm{a}, \mathrm{b}}$ and M. Hutchinson ${ }^{\mathrm{a}, \mathrm{b}}$
}

\begin{abstract}
${ }^{a}$ Department of Neurology, St Vincent's University Hospital, Dublin; ${ }^{\mathrm{b}}$ School of Medicine and Medical Sciences, University College Dublin, Dublin; ${ }^{\mathrm{c}}$ Trinity Centre for Bioengineering, Dublin and School of Mathematical Sciences, Dublin Institute of Technology, Dublin; ${ }^{\mathrm{d}}$ Beaumont Hospital, Dublin; ${ }^{\mathrm{e}}$ Mater Misericordiae University Hospital, Dublin; ${ }^{\mathrm{f}}$ Adelaide and Meath Hospital, Dublin; ${ }^{\mathrm{g}}$ Royal Victoria Eye and Ear Hospital, Dublin; ${ }^{\mathrm{h}}$ Cork University Hospital, Cork; and ${ }^{\mathrm{i}}$ Departments of Statistics, Trinity College Dublin, University of Limerick, Limerick, Ireland
\end{abstract}

\section{Keywords:}

adult onset idiopathic isolated focal dystonia, epidemiology, genetics, prevalence, primary dystonia, sex ratios

Received 27 April 2016 Accepted 9 August 2016

European Journal of Neurology 2017, 24: 73-81

doi:10.1111/ene.13133
Background: Adult onset idiopathic isolated focal dystonia presents with a number of phenotypes. Reported prevalence rates vary considerably; well-characterized cohorts are important to our understanding of this disorder. Aim: To perform a nationwide epidemiological study of adult onset idiopathic isolated focal dystonia in the Republic of Ireland.

Methods: Patients with adult onset idiopathic isolated focal dystonia were recruited from multiple sources. Diagnosis was based on assessment by a neurologist with an expertise in movement disorders. When consent was obtained, a number of clinical features including family history were assessed.

Results: On the prevalence date there were 592 individuals in Ireland with adult onset idiopathic isolated focal dystonia, a point prevalence of 17.8 per 100000 (95\% confidence interval 16.4-19.2). Phenotype numbers were cervical dystonia $410(69.2 \%)$, blepharospasm $102(17.2 \%)$, focal hand dystonia 39 (6.6\%), spasmodic dysphonia $18(3.0 \%)$, musician's dystonia $17(2.9 \%)$ and oromandibular dystonia six $(1.0 \%)$. Sixty-two $(16.5 \%)$ of 375 consenting index cases had a relative with clinically confirmed adult onset idiopathic isolated focal dystonia (18 multiplex and 24 duplex families). Marked variations in the proportions of patients with tremor, segmental spread, sensory tricks, pain and psychiatric symptoms by phenotype were documented.

Conclusions: The prevalence of adult onset idiopathic isolated focal dystonia in Ireland is higher than that recorded in many similar service-based epidemiological studies but is still likely to be an underestimate. The low proportion of individuals with blepharospasm may reflect reduced environmental exposure to sunlight in Ireland. This study will serve as a resource for international comparative studies of environmental and genetic factors in the pathogenesis of the disorder.

\section{Introduction}

Dystonia, characterized by sustained or intermittent muscle contractions causing abnormal repetitive

Correspondence: M. Hutchinson, Newman Clinical Research Professor, Department of Neurology, St Vincent's University Hospital, Elm Park, Dublin 4, Ireland (tel.: + 35312774179; fax: +35312773506; e-mail: mhutchin2@mac.com). movements and postures [1], is the third most frequent movement disorder. Primary dystonia refers to pure dystonia with no additional neurological signs other than tremor; adult onset isolated focal dystonia (AOIFD) is the commonest form of primary dystonia [2]. Although predominantly a sporadic disorder, up to $25 \%$ of AOIFD patients have a family member affected [3-5] and it is now considered autosomal 
dominant in inheritance with markedly reduced penetrance $[4,6]$. Although a number of genes implicated in primary dystonia have recently been identified [7-13] its pathogenesis remains elusive.

Adult onset isolated focal dystonia presents as a number of phenotypes including cervical dystonia (CD), focal hand dystonia (FHD), blepharospasm (BSP), spasmodic dysphonia (SD) and oromandibular dystonia (OMD). Owing to its heterogeneous clinical presentation and poor recognition by physicians, AOIFD is under-reported. Studies of the epidemiology of dystonia are often methodologically flawed, mixing primary focal, generalized and secondary causes of dystonia. Prevalence rates of primary dystonia range from 30 cases per million to 7320 per million [14-19]. Prevalence estimates of AOIFD (formerly adult onset primary torsion dystonia) range from 20 to 137 cases per million [16,17,20-23]. Genetic heterogeneity and variation in environmental exposures are possible explanations for this wide range [24,25]. Blepharospasm, for example, is more prevalent in studies from lower latitudes with high solar insolation [23,24,26-31]. Environmental exposures, sex and age at onset may interact with as yet unidentified genetic variants to influence phenotype and penetrance [32-34].

Improved understanding of pathogenesis and genetic causation requires well characterized patient cohorts. Thus the aim of this study was to determine comprehensively from multiple sources the clinical features, inheritance patterns and epidemiology of AOIFD in the Irish population for the first time.

\section{Participants and methods}

\section{Participant recruitment: sources}

There is currently no centralized, nationwide database of dystonia patients in Ireland. A database of patients attending a dystonia/botulinum toxin clinic in St Vincent's University Hospital, Dublin, has been established since 2001. In addition, patients with AOIFD were recruited from six neurology clinics and three ophthalmology clinics in hospitals throughout Ireland between 2011 and December 2014. These clinics are the principal specialist tertiary referral centres for neurology and ophthalmology in Ireland and were selected in an attempt to include all diagnosed dystonia patients. All consultant neurologists, ophthalmologists, neurophysiologists and botulinum toxin injection clinics, in both public and private practice, were repeatedly canvassed over a 5-year period (2010 2014) for participant recruitment. Members of the research team attended these clinics regularly and met with patients, or, following consent, patients were referred to the research team for participation by their treating physician. In addition, the self-help group, Dystonia Ireland, advertised the survey to their members.

Patients were questioned in relation to a possible family history of dystonia and there was further detailed questioning in order to identify family members with possible symptoms of any neurological condition or movement disorder. Consenting relatives living in Ireland of index patients who were reported, or suspected, to have a movement disorder by history were visited and examined by a member of the research team and, with further consent, were videotaped for later clinical analysis by two consultant neurologists (SO'R and $\mathrm{MH}$ ). Multiplex and duplex families were evaluated in this way and detailed pedigree diagrams were drawn up and stored.

\section{Diagnostic criteria}

Patients, aged 20 years or more, were diagnosed with AOIFD and phenotyped by a consultant neurologist with expertise in movement disorders [1]. Those with secondary dystonia, primary with onset prior to 20 years of age or with DYT1 dystonia were excluded (no other genetic testing was systematically used).

\section{Prevalence date}

The prevalence date was 31 December 2014 and all data refer to patients identified who were alive on that date. Prevalence rate calculations were based upon the total number of AOIFD patients; limited de-identified patient data (sex, date of birth, phenotype) provided by clinicians were included in prevalence calculations for those who did not consent to use of their full clinical information in the study.

\section{Methods}

Anonymised, encrypted data were collected, both prospectively at recruitment and retrospectively, through a combination of medical record review and patient history, following written informed consent. Data were entered in a dichotomous fashion in a database. Missing information was a result of either incomplete data in medical notes or patients who did not consent to full participation in this study. Those patients with AOIFD who did not consent to use of their data are included in the overall numbers in the study but their clinical information is not.

Data collected included current age, sex, phenotype, site at onset of initial dystonic symptoms, presence of 
spread of symptoms (but not time of spread as this was a retrospective study), age at symptom onset, presence of a sensory trick, coexisting upper limb tremor and pain. Patients were routinely questioned regarding a family history of any movement disorder. Patients were reported to have a family history of clinically confirmed dystonia if family members were assessed by a neurologist and given a clear diagnosis of dystonia. Patients who reported a relative with symptoms consistent with dystonia but who had not been assessed by a neurologist were referred to as having a family history of possible dystonia. A positive psychiatric history was based on a diagnosis documented in the medical notes and/or verbal report from a patient of a confirmed diagnosis of a psychiatric disorder by another physician.

DYT1 testing was performed only in patients with onset before 28 years or in patients with another affected family member with onset before 28 years of age; no other genetic testing was performed.

\section{Statistical analysis}

The point prevalence and age/sex-specific prevalence rates of AOIFD in the Republic of Ireland were calculated using population data acquired from the 2011 National Census (www.cso.i.e/en/census/census2011reports). Patient characteristics were analysed using ANOva and the Kruskal-Wallis test. The relationship between categorical variables was assessed using the chi-squared test. Post hoc analysis for ANOva was carried out using Fisher's least significant difference (LSD). For all tests the type I error rate was set at 0.05 , without correcting for multiple comparisons. Statistical analyses were carried out using SPSS (IBM SPSS statistics version 20).

\section{Ethics}

Ethical approval for this work was granted by the Ethics and Medical Research Committees, St Vincent's University Hospital, Dublin, and by ethics committees at all participating centres.

\section{Results}

\section{Participants recruited}

In all, 592 AOIFD patients who were alive on the prevalence date were identified. Of these, 507 patients consented for use of their data to calculate age/sexspecific prevalence rates; for 375 participants there was a full dataset available for clinical characteristics analysis.

\section{Prevalence of AOIFD in Ireland}

From the most recent census of the Republic of Ireland (Census 2011) the total population was 4588252 (3 $325821 \geq 20$ years of age). The point prevalence of AOIFD in those over the age of 20 years on 31 December 2014 (592 patients) was $0.0178 \%$ (17.8 per $100000 ; 95 \%$ confidence interval 16.4-19.2). Overall point prevalence was twice as high in women as in men $(0.021 \%$ vs. $0.0093 \%)$. The highest point prevalence in women was 58.4 per 100000 in the 65-69 year age group; in men the highest point prevalence was 37.9 per 100000 in the age group $\geq 85$ years (with a relatively small population denominator) (Table S1 and Fig. 1). The age/sex-specific prevalence rates for each 5-year period are graphically displayed in Fig. 1, which indicates clearly the overall predominance of women except in the 20-34 year quinquennia.

\section{Clinical characteristics of AOIFD patient population}

\section{Phenotypes}

Of the total 592 patients, the most common phenotype was CD with 410 individuals $(69.2 \%)$ followed by BSP 102 (17.2\%), FHD 39 (6.6\%), SD 18 (3.0\%), musician's dystonia (MD) $17(2.9 \%)$ and OMD six $(1.0 \%)$ (Table 1). All phenotypes occurred more frequently in women except MD, which was more common in men, and FHD, which was approximately equal between the sexes (Table S1 and Fig. 1). All FHD patients had task-specific writer's cramp.

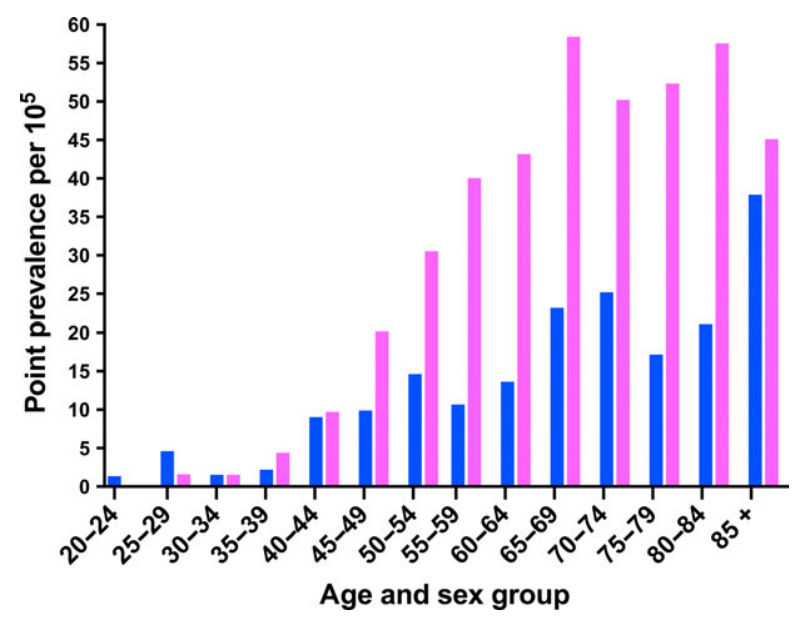

Figure 1 Histogram illustrating the age/sex prevalence of AOIFD (cases per 100000 population) in men and women within 5-year age groups in the Irish population (women, pink bars; men, blue bars). This illustrates the overall predominance of women in each quinquennium except for the 20-34 years age groups. 
Table 1 Clinical and demographic characteristics for each phenotype in the prevalence study

\begin{tabular}{lcccccc}
\hline Phenotype & CD & BSP & FHD & SD & MD & OMD \\
\hline Number of patients (592) & 410 & 102 & 39 & 18 & 17 & 6 \\
Female:male ratio & $2.6: 1$ & $3.1: 1$ & $1.2: 1$ & $5: 1$ & $0.6: 1$ & $5: 1$ \\
Number of patients with all data (375) & 291 & 33 & 21 & 10 & 16 & 4 \\
Mean age at onset (years) (SD) & $45.4(12.8)$ & $56.1(9.9)$ & $38.9(11.4)$ & $47.0(20.3)$ & $31.7(12.3)$ & $65.3(15.8)$ \\
Women: mean age at onset (years) (SD) & $46.3(12.1)$ & $54.4(10)$ & $41.7(11.8)$ & $44.6(20)$ & 40 & $65.3(15.8)$ \\
Men: mean age at onset (years) (SD) & $43.7(13.8)$ & $61.5(7.98)$ & $35.9(10.7)$ & 69 & $31.3(12.9)$ & N/A \\
Confirmed family history of dystonia (\%) & 17.2 & 18.2 & 9.5 & 30 & 0 & 25 \\
Segmental spread (\%) & 13.7 & 33.3 & 19.0 & 33.3 & 0 & 50 \\
Sensory trick (\%) & 59.5 & 21.2 & 4.8 & 0 & 0 & 25 \\
Associated upper limb tremor (\%) & 16.8 & 0 & 23.8 & 20 & 0 & 0 \\
Pain (\%) & 54.6 & 3.0 & 38.1 & 10.0 & 25.0 & 0 \\
Psychiatric comorbidity reported (\%) & 23.4 & 33.3 & 9.5 & 10.0 & 50 & 33.3 \\
Onset $<30$ years (\%) & 5.8 & 3.0 & 19.0 & 0 & 0
\end{tabular}

$\mathrm{CD}$, cervical dystonia; BSP, blepharospasm; FHD, focal hand dystonia; MD, musician's dystonia; SD, spasmodic dysphonia; OMD, oromandibular dystonia.

The full cohort consists of 592 individuals with adult onset idiopathic isolated focal dystonia in Ireland on the prevalence date. However, full clinical characteristics could only be determined for 375 individuals. Patients with cervical dystonia were more likely to consent to use of their clinical data in this study (than other phenotypes). Note the tendency for an earlier mean age of onset in men (than women) in focal hand dystonia, musician's dystonia and cervical dystonia.

\section{Associated clinical features in 375 (of 592) patients with full data}

Age at onset

The oldest mean age at onset in our cohort occurred in patients with OMD (65.3 years), followed by BSP (56.1 years), SD (47.0 years), CD (45.4 years) and FHD (38.9 years) (Table 1). The data were submitted to a one-way ANOVA, which confirmed an overall significant difference in age of onset between the various sites of dystonia onset $[F(5,369)=11.6 ; P<0.001]$. In Fisher's LSD post hoc analysis the same degree of statistical difference was again seen between all phenotypes except for BSP versus OMD, CD versus SD, SD versus FHD and FHD versus MD where difference in mean age of onset did not reach significance. A younger mean age of onset of dystonia in men versus women was found for all phenotypes except BSP and SD. In our CD cohort men were, on average, 3 years younger than women when they first developed symptoms with a mean age of onset of 43.7 years in men and 46.3 years in women (Table 1 ).

\section{Other clinical features}

A sensory trick was found in $59.5 \%$ of $\mathrm{CD}, 21.2 \%$ of BSP and $4.8 \%$ of FHD $(P<0.0001$ across phenotypes, Kruskal-Wallis, $17.4 \%$ effect size). A proportion of CD, FHD and SD patients were noted to have a concomitant upper limb tremor $[16.8 \%, 23.8 \%$ and $20 \%$, respectively $(P=0.041$ across groups, Kruskal-Wallis, $3.13 \%$ effect size)]. There was no significant influence of age of onset $(P=0.396)$ and sex $(P=0.806)$ on the occurrence of upper limb tremor.
Rates of pain varied across all six phenotypes $(P<0.0001$, Kruskal-Wallis $)$ with phenotype accounting for $15.8 \%$ of the variance. Pain was most prevalent in those with $\mathrm{CD}(54.6 \% ; P<0.001)$ and FHD (38.1\%). On post hoc analysis the frequency of pain in CD and FHD remained significant compared to other phenotypes except for $\mathrm{CD}$ versus FHD $(P=0.143)$ and FHD versus OMD $(P=0.142)$.

\section{Self-reported psychiatric symptoms requiring medical advice}

Self-reported psychiatric symptoms requiring medical advice were common across all phenotypes but were most prevalent in BSP, CD and OMD although there were no statistically significant differences across the groups ( $P=0.248$, Kruskal-Wallis). Depression and anxiety were the most commonly reported psychiatric comorbidities. There was no significant association between pain and psychiatric comorbidity $(P=0.210)$.

\section{Segmental spread}

Spread of dystonic symptoms was most commonly seen in those with OMD (50\%), BSP (33.3\%) and SD $(33.3 \%)$ with lower rates of $13.7 \%$ and $19 \%$ in CD and FHD $(P=0.005$ across groups, Kruskal-Wallis, $4.42 \%$ effect size). This remained significant on post hoc (chi-squared) analysis between phenotypes for CD versus BSP $(P=0.003)$, CD versus OMD $(P=0.040)$, BSP versus MD $(P=0.009)$, SD versus MD $(P=0.022)$ and for MD versus OMD $(P=0.004)$. There was a significant correlation between segmental spread and the presence of upper limb tremor $(P<0.001)$. The mean age at onset of those who 
experienced spread of their dystonia was 47.36 years (SD 13.19) versus those without spread at 45.4 years (SD 13.0) $(P=0.291)$. Disease duration had a significant impact on spread; patients without symptom spread had average disease duration of 14.4 years (SD 9.6) on the prevalence date, whilst those with spread of their dystonia had average disease duration of 19.9 years (SD 12.3; $P<0.001)$. Sex did not influence spread of dystonic symptoms $(P=0.949)$.

\section{Family history}

Some 134/375 (35.7\%) patients with a full dataset reported a family history of a movement disorder; $62 / 375(16.5 \%)$ had clinically confirmed AOIFD in a relative (Fig. 2). Eighteen multiplex families with three or more individuals affected with AOIFD and another 24 duplex families with two individuals affected were identified. Affected relatives deceased or living outside Ireland were identified and are included in the reporting of the frequency of a positive family history but were not included in other aspects of the epidemiological survey.

\section{Genetic architecture}

All of the 18 multiplex families had a possible autosomal dominant mode of inheritance with reduced penetrance. Mitochondrial inheritance was also a possible mode of transmission in 14 of these 18 pedigrees but many offspring had not yet reached the age for risk of onset of AOIFD. Phenotypic heterogeneity was observed within the pedigrees (Table 2). All affected members of 18 families (five multiplex, 13 duplex) had CD only, whilst seven families had CD and FHD and another six families had $\mathrm{CD}$ and SD. The mean age at onset in the CD patients with a clinically confirmed

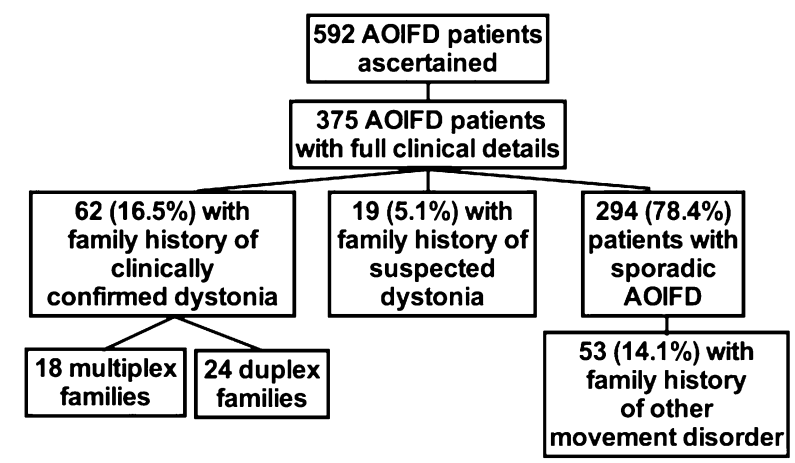

Figure 2 Flowchart illustrating the disposition of the total number of 592 ascertained patients with adult onset idiopathic isolated focal dystonia (AOIFD), the subgroup of 375 patients with full clinical details, the 62 patients with clinically confirmed familial AOIFD and the 19 patients with a family history of suspected AOIFD. family history of dystonia (41.8 years; SD 12.1) was 4.2 years earlier than the mean age of onset of sporadic $\mathrm{CD}$ patients (46.0 years; $\mathrm{SD} 12.7)[F(1,227)$ $=4.00 ; P=0.047$, one-way ANOvA $]$.

\section{Discussion}

\section{Point prevalence rate}

In this study the prevalence of AOIFD in Ireland has been determined following an intensive recruitment of eligible patients over a 5-year period. A point prevalence of 17.8 per 100000 was calculated, similar to other service-based studies [21,22,35-37]. A recent meta-analysis of prevalence studies of primary dystonia estimated a prevalence rate of 16.43 per 100000 (95\% confidence interval 12.09-22.32) [19]; our point prevalence rate is remarkably similar. Through participation of all the neurology, specialist botulinum toxin and movement disorder outpatient clinical services in the country an attempt was made to limit the number of potentially missed cases. Service-based studies remain the most practical method of prevalence estimation; record linkage or door-to-door studies are limited by diagnostic inaccuracy, small denominators and over-ascertainment, with marked variation in prevalence estimates. Prevalence rates of AOIFD depend on expert neurological assessment but are also totally dependent on patient referral from primary

Table 2 Phenotypic composition of the 42 familial adult onset idiopathic isolated focal dystonia (AOIFD) pedigrees ascertained in the prevalence study from 42 consenting index cases (18 multiplex and 24 duplex pedigrees)

\begin{tabular}{|c|c|c|}
\hline $\begin{array}{l}\text { Phenotypes seen in } \\
\text { pedigree }\end{array}$ & $\begin{array}{l}\text { Number of } \\
\text { multiplex pedigrees } \\
\text { with phenotypes }\end{array}$ & $\begin{array}{l}\text { Number of duplex } \\
\text { pedigrees with } \\
\text { phenotypes }\end{array}$ \\
\hline CD only & 5 & 13 \\
\hline FHD only & - & 1 \\
\hline BSP only & - & 1 \\
\hline $\mathrm{CD}+\mathrm{SD}$ & 5 & 1 \\
\hline $\mathrm{CD}+\mathrm{FHD}$ & 2 & 5 \\
\hline $\mathrm{CD}+\mathrm{BSP}$ & 2 & - \\
\hline $\mathrm{CD}+\mathrm{FHD}+\mathrm{BSP}$ & 1 & - \\
\hline $\begin{array}{l}\mathrm{CD}+\mathrm{UL} \text { dystonic } \\
\text { tremor }\end{array}$ & 1 & - \\
\hline $\mathrm{CD}+\mathrm{SD}+\mathrm{OMD}$ & 1 & - \\
\hline $\begin{array}{l}\mathrm{CD}+\mathrm{SD}+\mathrm{CD}+\mathrm{UL} \\
\text { tremor }\end{array}$ & 1 & - \\
\hline CD + axial dystonia & - & 1 \\
\hline $\mathrm{CD}+\mathrm{BSP}+\mathrm{OMD}$ & - & 1 \\
\hline $\mathrm{CD}+\mathrm{BSP}+\mathrm{OMD}+\mathrm{SD}$ & - & 1 \\
\hline Total & 18 & 24 \\
\hline
\end{tabular}

BSP, blepharospasm; CD, cervical dystonia; FHD, focal hand dystonia; OMD, oromandibular dystonia; SD, spasmodic dysphonia; UL, upper limb. 
healthcare practitioners. For that reason our study is an underestimate of the true prevalence; many individuals with milder forms of FHD, for example, are unlikely to seek medical attention.

\section{Prevalence of phenotypes: environmental effects?}

Cervical dystonia was by far the most commonly observed phenotype. There was a relatively low prevalence of BSP compared to that reported from southern Europe [38], despite repeated determined efforts to recruit these patients through specialist ophthalmology clinics in all parts of Ireland. This low proportion of BSP is therefore considered not to be the result of referral bias but rather reflects a true low prevalence. Given the relatively high rate of immigration and emigration from Ireland over centuries it is unlikely that this represents a genetic isolate. It is hypothesized that it is a consequence of lower sunlight exposure in Ireland [24]. The ratio of BSP to total CD plus BSP patients ascertained in this study $(102 / 512=0.20)$ is within the confidence limits of the ratio predicted from the average first quarter solar insolation reported in Ireland $\left(1.4 \mathrm{kWh} / \mathrm{m}^{2} /\right.$ day) (see Fig. 3, derived from reference 24, Fig. 2).

\section{Age-related sexual dimorphism of sex ratios in AOIFD}

Overall in this study (as in other epidemiological reports) women were more frequently affected with AOIFD than men with the exception of an almost equal ratio in FHD and a male predominance in MD. The ratio of women to men affected with $\mathrm{CD}$ was 2.6:1 which is slightly higher than previously reported $[15,21,29,39,40]$. Men had an earlier mean age at onset in $\mathrm{CD}, \mathrm{FHD}$ and MD than women; men were approximately 3 years younger at mean age of onset than women in our CD cohort. A younger age of onset in men has been demonstrated in other $\mathrm{CD}$ populations $[40,41]$; the reasons for this are not known. Theories include possible protective hormonal or genetic sex effects. Sexual dimorphism in the sex ratios of AOIFD phenotypes has been noted for many years with a male predominance in FHD and MD along with a steadily increasing female:male sex ratio with increasing mean age of onset in the phenotypes CD, BSP and OMD. Temporal discrimination thresholds show similar sexual dimorphism [42], a measure found to be abnormal in AOIFD patients [43-45] and their unaffected first-degree relatives. The sexual dimorphism seen in temporal processing of sensory stimuli in both healthy control subjects [42] and unaffected relatives of AOIFD patients [45] seems to parallel age-related sexual dimorphism of sex ratios observed in AOIFD.

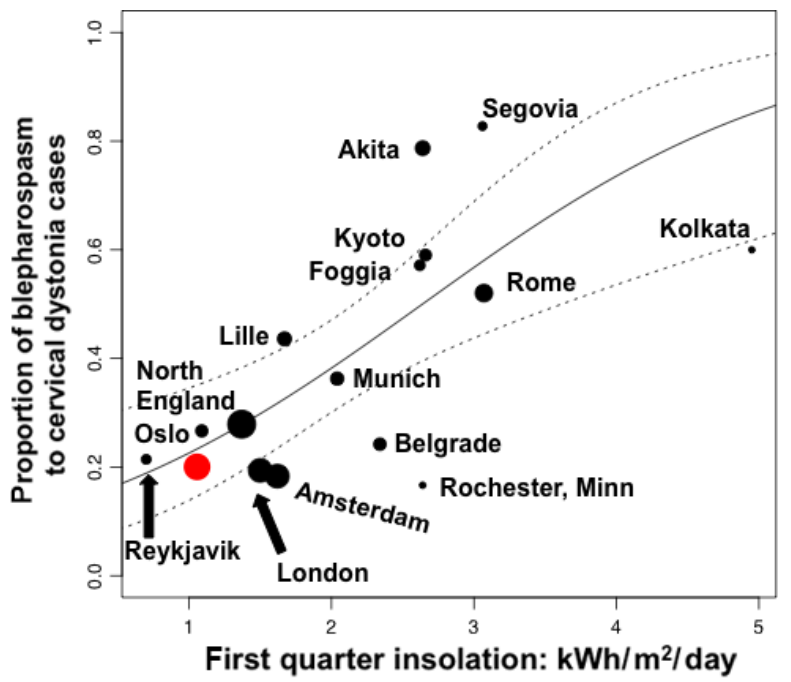

Figure 3 This graph (derived from reference 24, Fig. 2) illustrates the association between the blepharospasm:cervical dystonia phenotype ratio (the ratio of the number of blepharospasm patients to the total number of cervical dystonia and blepharospasm patients) and quarter-one insolation measured as $\mathrm{kWh} / \mathrm{m}^{2} /$ day for study sites throughout the northern hemisphere. The ratio of blepharospasm to total cervical dystonia plus blepharospasm patients ascertained in the present study $(102 / 512=0.20)$ (red filled circle) is within the confidence limits of the ratio predicted from the average first quarter insolation reported in Ireland $\left(1.4 \mathrm{kWh} / \mathrm{m}^{2} /\right.$ day $)$. The black circles show data from each of the studies with the diameter of the circles proportional to the square root of the total number of individuals in each study. The solid line is the fitted meta-regression back transformed from the logit scale. The dashed lines are the $95 \%$ confidence intervals for the mean association back transformed to the original scale.

\section{Sensory tricks}

The reported prevalence of sensory tricks was similar to that found in previous studies $[28,46]$. The physiology of such alleviating manoeuvres in dystonia has been suggested to involve modulation of abnormally increased facilitation [47,48]; detailed characterization of the neurophysiological mechanisms of such alleviating manoeuvres would contribute to increased understanding of sensorimotor integration in dystonia.

\section{Segmental spread}

The observed rate of segmental spread was, as expected, highest in OMD and BSP [49]. Although data on time elapsed from symptom onset to segmental spread was not recorded, our findings of increased disease duration in those who developed segmental spread is in line with other studies reporting age as an independent factor for spread [50]. 


\section{Tremor}

Upper limb tremor occurred in association with AOIFD in $16.8 \%$ and $20 \%$ of $\mathrm{CD}$ and SD patients respectively. Overall rates of tremor reported (both dystonic tremor and tremor associated with dystonia), vary considerably and range from $10 \%$ to $85 \%$ $[26,51,52]$. In a large Italian dystonia cohort there was an overall prevalence of tremor at $16.7 \%$, but only $5.8 \%$ with upper limb tremor [26]. Tremor was reported in almost $24 \%$ of the FHD patients; it is suspected that this is an artefact of referral bias. Overall FHD is likely to be under-ascertained in a servicebased epidemiological survey. Patients with FHD and associated tremor are more likely to be referred by general practitioners whereas FHD patients without tremor are less likely to be recognized in the community.

\section{Pain}

The high rates of pain and coincident psychiatric conditions highlight the overall burden of dystonia and the importance of screening for these in the clinical setting and employing a multidisciplinary approach to treatment of AOIFD. Interestingly there was no statistically significant relationship observed between the two, indicating that the processes involved in their development are independent of each other.

\section{Genetic aspects}

Sixty-two patients who had another family member with a confirmed diagnosis of AOIFD were identified, representing $16.5 \%$ of our cohort. None of these patients had a secondary or identifiable genetic cause for their dystonia. This is probably an underestimation of the proportion of familial cases; in a further 19 patients a family history of dystonia was deemed suspicious but could not be confirmed for a number of reasons (refusal to participate, living abroad). A family history of dystonia in these remaining 19 patients cannot be confirmed; Leube and colleagues suggest that patient report is likely to significantly underestimate actual rates of dystonia amongst family members [6]. Reported rates of family history of dystonia in seemingly sporadic AOIFD vary from $26.1 \%$ [53], $18 \%$ [6] to $9.1 \%$ [28]. The patterns of inheritance observed in this study would support an autosomal dominant transmission of genes predisposing to dystonia, with reduced penetrance. Although some of the multiplex pedigrees might appear to support a mitochondrial inheritance pattern, many of the probands' offspring had not yet reached the age at which the disorder would be penetrant. Evidence from abnormal temporal discrimination thresholds in unaffected first-degree relatives of patients with AOIFD would also support an autosomal dominant inheritance with reduced penetrance $[44,45]$. Further understanding of the patterns of disease penetrance, including the influence of gender, in AOIFD will add to our knowledge of the aetiopathology of this multifactorial condition. The CD patients were not sub-divided with regard to the presence or absence of head tremor and the observation that patients with tremulous $\mathrm{CD}$, compared to those without head tremor, are more likely to be familial cannot be confirmed [54].

An earlier age at onset in patients with a confirmed family history of dystonia could be indicative of as yet undiscovered genetic variants with higher penetrance. However, more probably, an increased awareness of the condition in relatives of affected patients and identification of asymptomatic affected relatives by the research team prior to seeking medical attention may also have contributed to the finding of an earlier age at onset in familial cases.

\section{Limitations}

This was a service-based study and therefore is probably an underestimate of the true prevalence of AOIFD, as it does not take into account those who have not sought medical attention or have not attended a specialist. There may also be a referral bias as patients were recruited mainly through neurology, botulinum toxin and ophthalmology outpatient clinics, with perhaps an underestimate in particular of the prevalence of SD as ear, nose and throat clinics were not routinely included in our recruitment process. Full clinical information was missing or not included due to lack of full consent in 217/592; as a result the prevalence of clinical characteristics described in Table 1 is open to error. However, this is considered unlikely as 375 patients represent a significant cohort and the prevalence rates are similar to, or greater than, those reported elsewhere.

\section{Conclusion}

The clinical characteristics of a large population of patients with primary AOIFD are described and, for the first time in an Irish population, prevalence data are reported. Detailed characterization of disease with identification of patient subgroups based on phenotype, age at onset, mode of inheritance and other clinical features is vital to inform future genetic studies and guide research. 


\section{Acknowledgements}

We thank the patients, their relatives and the control participants for giving their time in this study.

This work was supported by grants from Dystonia Ireland, Health Research Board Ireland (CSA-2012-5) and Foundation for Dystonia Research (Belgium).

\section{Disclosure of conflicts of interest}

Laura Williams, Okka Kimmich, Ines Beiser, Eavan McGovern, John Butler, Fiona Molloy, Dan Healy, Helena Moore, Richard Walsh and Terence McSwiney have no disclosures. Michael Hutchinson serves as associate editor of the Multiple Sclerosis Journal, has received speakers' honoraria from Biogen-Idec, BayerSchering and Novartis and receives research grants from Dystonia Ireland, the Health Research Board of Ireland (CSA-2012-5), the Foundation for Dystonia Research (Belgium) and the Irish Institute of Clinical Neuroscience. Tim Lynch reports receiving educational grants from Bayer Schering, Biogen Idec, Lundbeck, Medtronic; research grants from the Irish Institute of Clinical Neuroscience, Mater College, PRTL1 funding; speakers' honoraria from Novartis UCB Pharma, Teva, Merck Serono and Biogen Idec. Sean O'Riordan reports receiving a speaker's honorarium from Abbvie.

\section{Supporting Information}

Additional Supporting Information may be found in the online version of this article:

Table S1. Point prevalence of adult onset isolated focal dystonia (AOIFD) in Ireland for men and women by age groups in quinquennia illustrating the effects of age and gender on the age/sex-specific point prevalence rates.

\section{References}

1. Albanese A, Bhatia K, Bressman SB, et al. Phenomenology and classification of dystonia: a consensus update. Mov Disord 2013; 28: 863-873.

2. Bressman SB. Dystonia genotypes, phenotypes, and classification. Adv Neurol 2004; 94: 101-107.

3. Stojanović M, Cvetković D, Kostić VS. A genetic study of idiopathic focal dystonias. J Neurol 1995; 242: 508-511.

4. Waddy HM, Fletcher NA, Harding AE, Marsden CD. A genetic study of idiopathic focal dystonias. Ann Neurol 1991; 29: 320-324.

5. Defazio G, Livrea P, Guanti G, Lepore V, Ferrari E. Genetic contribution to idiopathic adult-onset blepharospasm and cranial-cervical dystonia. Eur Neurol 1993; 33: 345-350.
6. Leube B, Kessler KR, Goecke T, Auburger G, Benecke R. Frequency of familial inheritance among 488 index patients with idiopathic focal dystonia and clinical variability in a large family. Mov Disord 1997; 12: 10001006.

7. Almasy L, Bressman SB, Raymond D, et al. Idiopathic torsion dystonia linked to chromosome 8 in two Mennonite families. Ann Neurol 1997; 42: 670-673.

8. Xiromerisiou G, Houlden H, Scarmeas N, et al. THAP1 mutations and dystonia phenotypes: genotype phenotype correlations. Mov Disord 2012; 27: 1290-1294.

9. Hersheson J, Mencacci NE, Davis M, et al. Mutations in the autoregulatory domain of $\beta$-tubulin $4 \mathrm{a}$ cause hereditary dystonia. Ann Neurol 2013; 73: 546-553.

10. Bentivoglio AR, Ialongo $\mathrm{T}$, Contarino MF, Valente EM, Albanese A. Phenotypic characterization of DYT13 primary torsion dystonia. Mov Disord 2004; 19: 200206.

11. Khan NL, Wood NW, Bhatia KP. Autosomal recessive, DYT2-like primary torsion dystonia: a new family. Neurology 2003; 61: 1801-1803.

12. Norgren N, Mattson E, Forsgren L, Holmberg M. A high-penetrance form of late-onset torsion dystonia maps to a novel locus (DYT21) on chromosome 2q14.3q21.3. Neurogenetics 2011; 12: 137-143.

13. Chouery E, Kfoury J, Delague V, et al. A novel locus for autosomal recessive primary torsion dystonia (DYT17) maps to 20p11.22-q13.12. Neurogenetics 2008; 9: 287-293.

14. Defazio G, Abbruzzese G, Livrea P, Berardelli A. Epidemiology of primary dystonia. Lancet Neurol 2004; 3: 673-678.

15. Asgeirsson H, Jakobsson F, Hjaltason H, Jonsdottir H, Sveinbjornsdottir S. Prevalence study of primary dystonia in Iceland. Mov Disord 2006; 21: 293-298.

16. Nutt JG, Muenter MD, Aronson A, Kurland LT, Melton LJ. Epidemiology of focal and generalized dystonia in Rochester, Minnesota. Mov Disord 1988; 3: 188-194.

17. Fukuda H, Kusumi M, Nakashima K. Epidemiology of primary focal dystonias in the western area of Tottori Prefecture in Japan: comparison with prevalence evaluated in 1993. Mov Disord 2006; 21: 1503-1506.

18. Müller J, Kiechl S, Wenning GK, et al. The prevalence of primary dystonia in the general community. Neurology 2002; 59: 941-943.

19. Steeves TD, Day L, Dykeman J, Jette N, Pringsheim T. The prevalence of primary dystonia: a systematic review and meta-analysis. Mov Disord 2012; 27: 1789-1796.

20. Wang L, Chen Y, Hu B, Hu X. Late-onset primary dystonia in Zhejiang province of China: a service-based epidemiological study. Neurol Sci 2016; 37: 111-116.

21. Pekmezović T, Ivanović N, Svetel M, et al. Prevalence of primary late-onset focal dystonia in the Belgrade population. Mov Disord 2003; 18: 1389-1392.

22. Epidemiological Study of Dystonia in Europs (ESDE) Collaborative Group. A prevalence study of primary dystonia in eight European countries. J Neurol 2000; 247: 787-792.

23. Papantonio AM, Beghi E, Fogli D, et al. Prevalence of primary focal or segmental dystonia in adults in the district of Foggia, southern Italy: a service-based study. Neuroepidemiology 2009; 33: 117-123.

24. Molloy A, Williams L, Kimmich O, et al. Sun exposure is an environmental factor for the development of 
blepharospasm. J Neurol Neurosurg Psychiatry 2016; 87: 420-424.

25. Petrucci S, Valente EM. Genetic issues in the diagnosis of dystonias. Front Neurol 2013; 4: 34.

26. Defazio G, Gigante AF, Abbruzzese G, et al. Tremor in primary adult-onset dystonia: prevalence and associated clinical features. J Neurol Neurosurg Psychiatry 2013; 84: 404-408.

27. Sugawara M, Watanabe S, Toyoshima I. Prevalence of dystonia in Akita Prefecture in Northern Japan. Mov Disord 2006; 21: 1047-1049.

28. Groen JL, Kallen MC, van de Warrenburg BPC, et al. Phenotypes and genetic architecture of focal primary torsion dystonia. J Neurol Neurosurg Psychiatry 2012; 83: 1006-1011.

29. Butler AG, Duffey PO, Hawthorne MR, Barnes MP. An epidemiologic survey of dystonia within the entire population of northeast England over the past nine years. Adv Neurol 2004; 94: 95-99.

30. Soland VL, Bhatia KP, Marsden CD. Sex prevalence of focal dystonias. J Neurol Neurosurg Psychiatry 1996; 60: 204-205.

31. Duffey PO, Butler AG, Hawthorne MR, Barnes MP. The epidemiology of the primary dystonias in the north of England. Adv Neurol 1998; 78: 121-125.

32. Defazio G, Abbruzzese G, Aniello MS, et al. Environmental risk factors and clinical phenotype in familial and sporadic primary blepharospasm. Neurology 2011; 77: 631-637.

33. Defazio G, Berardelli A, Abbruzzese G, et al. Possible risk factors for primary adult onset dystonia: a case-control investigation by the Italian Movement Disorders Study Group. J Neurol Neurosurg Psychiatry 1998; 64: 25-32.

34. Tanner K, Roy N, Merrill RM, et al. Risk and protective factors for spasmodic dysphonia: a case-control investigation. J Voice 2011; 25: e35-e46.

35. Defazio G, Livrea P, De Salvia R, et al. Prevalence of primary blepharospasm in a community of Puglia region, Southern Italy. Neurology 2001; 56: 1579 1581.

36. Castelon Konkiewitz E, Trender-Gerhard I, Kamm C, et al. Service-based survey of dystonia in Munich. Neuroepidemiology 2002; 21: 202-206.

37. Le K-D, Nilsen B, Dietrichs E. Prevalence of primary focal and segmental dystonia in Oslo. Neurology 2003; 61: 1294-1296.

38. Defazio G, Gigante AF. The environmental epidemiology of primary dystonia. Tremor Other Hyperkinet Mov ( $N$ Y) 2013; 3: pii: tre-03-131-3076-1.

39. Matsumoto S, Nishimura M, Shibasaki H, Kaji R. Epidemiology of primary dystonias in Japan: comparison with western countries. Mov Disord 2003; 18: 1196-1198.
40. Epidemiologic Study of Dystonia in Europe (ESDE) Collaborative Group. Sex-related influences on the frequency and age of onset of primary dystonia.. Neurology 1999; 53: 1871-1873.

41. Defazio G, Abbruzzese G, Girlanda P, et al. Does sex influence age at onset in cranial-cervical and upper limb dystonia? J Neurol Neurosurg Psychiatry 2003; 74: 265 267.

42. Williams LJ, Butler JS, Molloy A, et al. Young women do it better: sexual dimorphism in temporal discrimination. Front Neurol 2015; 6: 160.

43. Bradley D, Whelan R, Kimmich $\mathrm{O}$, et al. Temporal discrimination thresholds in adult-onset primary torsion dystonia: an analysis by task type and by dystonia phenotype. J Neurol 2012; 259: 77-82.

44. Kimmich O, Bradley D, Whelan R, et al. Sporadic adult onset primary torsion dystonia is a genetic disorder by the temporal discrimination test. Brain 2011; 134(Pt 9): 2656-2663.

45. Kimmich O, Molloy A, Whelan R, et al. Temporal discrimination, a cervical dystonia endophenotype: penetrance and functional correlates. Mov Disord 2014; 29: 804-811.

46. Patel N, Hanfelt J, Marsh L, Jankovic J. Alleviating manoeuvres (sensory tricks) in cervical dystonia. $J \mathrm{Neu}$ rol Neurosurg Psychiatry 2014; 85: 882-884.

47. Ramos VFML, Karp BI, Hallett M. Tricks in dystonia: ordering the complexity. J Neurol Neurosurg Psychiatry 2014; 85: 987-993.

48. Amadio S, Houdayer E, Bianchi F, et al. Sensory tricks and brain excitability in cervical dystonia: a transcranial magnetic stimulation study. Mov Disord 2014; 29: 11851188 .

49. Svetel M, Pekmezović T, Jović J, et al. Spread of primary dystonia in relation to initially affected region. J Neurol 2007; 254: 879-883.

50. Martino D, Berardelli A, Abbruzzese G, et al. Age at onset and symptom spread in primary adult-onset blepharospasm and cervical dystonia. Mov Disord 2012; 27: $1447-1450$

51. Erro R, Rubio-Agusti I, Saifee TA, et al. Rest and other types of tremor in adult-onset primary dystonia. $J \mathrm{Neu}$ rol Neurosurg Psychiatry 2014; 85: 965-968.

52. Rudzińska $M$, Krawczyk $M$, Wójcik-Pedziwiatr $M$, Szczudlik A, Wasielewska A. Tremor associated with focal and segmental dystonia. Neurol Neurochir Pol 2013; 47: 223-231.

53. Camargo CHF, Camargos ST, Becker N, et al. Cervical dystonia: about familial and sporadic cases in 88 patients. Arq Neuropsiquiatr 2014; 72: 107-113.

54. Rubio-Agusti I, Pareés I, Kojovic M, et al. Tremulous cervical dystonia is likely to be familial: clinical characteristics of a large cohort. Parkinsonism Relat Disord 2013; 19: 634-638. 